\title{
A Vibration Model of Ball Bearings with a Localized Defect Based on the Hertzian Contact Stress Distribution
}

\author{
Fanzhao Kong, Wentao Huang $(\mathbb{D}$, Yunchuan Jiang, Weijie Wang, and Xuezeng Zhao \\ School of Mechatronics Engineering, Harbin Institute of Technology, 92 West Dazhi Street, Harbin 150001, China \\ Correspondence should be addressed to Wentao Huang; hwt@hit.edu.cn
}

Received 27 July 2017; Revised 5 February 2018; Accepted 28 February 2018; Published 1 April 2018

Academic Editor: Naveed Ahmad

Copyright (C) 2018 Fanzhao Kong et al. This is an open access article distributed under the Creative Commons Attribution License, which permits unrestricted use, distribution, and reproduction in any medium, provided the original work is properly cited.

To study the vibration mechanism of ball bearings with localized defects, a vibration model of a ball bearing based on the Hertzian contact stress distribution is proposed to predict the contact force and vibration response caused by a localized defect. The calculation of the ball-raceway contact force when the ball passes over the defect is key to establishing a defect vibration model. Hertzian contact theory indicates that the contact area between the ball and the raceway is an elliptical contact surface; therefore, a new approach is used to calculate the ball-raceway contact force in the defect area based on the stress distribution and the contact area. The relative motion between the inner ring, the outer ring, and the balls is considered in the proposed model, and the Runge-Kutta algorithm is used to solve the vibration equations. In addition, vibration experiments of a bearing with an outer ring defect under different loads are performed. The numerical signals and experimental signals are compared in the time and frequency domains, and good correspondence between the numerical and experimental results is observed. Comparisons between the traditional model and the proposed model reveal that the proposed model provides more reasonable results.

\section{Introduction}

The failure of a properly installed and lubricated bearing occurs in the form of surface fatigue cracks, such as spalls and pits [1]. In a ball bearing, spalls and pits often form on the contact surfaces between the raceways and balls. The variation of the contact deformation between the ball and the raceway when the ball passes over a defect causes a sudden change in the contact force, which causes periodic vibration of the bearing. How to describe and explain this process using mathematical and physical models is a major area of research on bearings with defects.

In early studies $[2,3]$, the variation of the fault signals of bearing defects in the frequency domain was analysed in detail. Subsequently, a vibration model of bearings was introduced. The research focused on the periodic vibration phenomenon in bearings, and an impulse was used to describe the impact force caused by a localized defect. Rafsanjani et al. [4] developed a vibration model of ball bearings, studied the vibration characteristics of localized defects on the inner ring, outer ring, and balls, and established a pulse function that contains several parameters, such as the position, angle, and depth of the defects. Tandon and Choudhury $[5,6]$ used a rectangular pulse, a triangular pulse, and a half-sine pulse to express the impact force caused by localized defects, correlated the severity of the defect and the defect generation time with the amplitude of the pulse, and calculated the width of the pulse from the width of the defect. The results showed that the vibration amplitude of the outer raceway's defect expressed by the rectangular pulse is greater than that expressed by the half-sine pulse.

Although the periodic vibration of a bearing due to a fault can be simulated somewhat by pulse functions, the geometric morphology of defects cannot be adequately described, and the generation of the impact force cannot be adequately explained; thus, current research focuses on simulating the impact process via mechanical calculations. In previous studies [7-17], scholars suggested that when a ball passes over a defect on the raceway, the ball will sink to a certain depth, and the contact deformation between the ball and raceway will change, resulting in a change in the ball-raceway contact force; this process causes periodic vibration of the bearings. Sawalhi and Randall $[7,8]$ presented a gearbox model with bearing faults and compared it with the model 
in [9]. In [9], when the rolling element enters or exits the spall region, the contact force between the elements and the raceways will change instantly, which can cause sharp vibrations in the gearbox system. This model predicts very large impulsive forces in the system as a result of the sharp increase in acceleration required to maintain a balance within the system. Thus, they updated the model to reflect the actual path of the rolling element and defined the depth of the defect as a gradient function associated with the width of the defect, the rolling element's radius, and the race radius. Patel et al. [10] reported a dynamic model of ball bearings with single and double defects on the raceways; a fixed sinking depth of the balls was obtained based on the defect width and the ball radius. Patel et al. [11] updated the model by considering the profile of a localized defect and assigning a variable defect depth based on the variable size of the defect and the ball radius. The simulation results in these two papers are generally consistent with the experimental results. Patil et al. [12] proposed a ball bearing model with a localized defect to predict the vibration response. In this model, the defect is modelled as a circumferential half sinusoidal wave, and the vibration amplitude of the ball is calculated based on the angle of the defect, the rotational speed of the balls, and the defect width. The experimental results showed that the greater the defect width is, the larger the vibration amplitude of the fault signal is. Moazen Ahmadi et al. [13] established a nonlinear dynamic model of roller bearings with a wider range of defects. The model considers the finite size of the rollers, the contact force, and the damping force between the rolling elements and raceways to calculate the path and contact force of rollers in the defect region. Comparisons between the proposed model, the point mass model, and experimental results were performed and showed that the proposed model is more reasonable than the point model; the numerical results are more consistent with the experimental results. Liu et al. [14] proposed that the vibration amplitude and duration of the impact force are determined by the geometric profile and size of the defects. Based on the geometric profile and size of the defects, ball-defect contacts were divided into five types; moreover, the sinking depth of the ball was expressed by piecewise functions according to the number of contact points between the balls and the defects, and the contact stiffness of each type was calculated to obtain the contact force. Gomez et al. [15] presented a deep groove ball bearing model with localized defects to study the instantaneous angular speed variations of the balls. This model used a simple localized defect model with a rigidly defect depth, and the defect depth is also regarded as the variation of the contact deformation when the balls pass over the defect. Mishra et al. [16] proposed three different ball bearing defect models, a 5-DOF vibration model developed in MATLAB Simulink, a multibody dynamics model using bond graph by SYMBOLS software, and a multibody CAD model using ADAMS software. The simulated and the experimental vibration signals of different bearing faults are also compared. However, the ball-raceway contact deformation has a constant value when the balls pass over the defect in the vibration model. Chen and Kurfess [17] proposed a new rolling element bearing model to estimate the defect size on the outer raceway. The vibration signal from the time domain is used to estimate the defect size. The experiment results showed that this model provides accurate estimation.

In the studies described above, the contact forces between the balls and the defects are calculated based on the sinking depth of the balls, which is related to the defect width and the ball radius. The advantage of this approach is that it can calculate the impact forces of defects with different sizes; however, the disadvantage of this approach is that regardless of how the load applied to the bearing changes, the rigidly sinking depth of the ball is unchanged in the defect area. To solve this problem, a vibration model of a bearing with a defect that uses Hertzian contact stress distribution is proposed. The new model considers the contact area and the stress distribution. It includes several important parameters, the defect width and the ball radius, as well as the bearing load, the defect geometry, and the shaft rotational speed. In the new model, the load on the bearings can affect the sinking depth of the balls, and the geometric relationship between the balls, raceways, and defects is different from that in the traditional models.

This paper is divided into six sections. The second section presents the analysis of the contact process between a ball and a defect, and the third section introduces the contact model of balls and raceways. An experiment is presented in the fourth section. In the fifth section, the numerical results of the proposed model are analysed, and the experimental results and the numerical results are compared. The last section presents the conclusions.

\section{Analysis of the Contact Process between the Ball and Defect Area}

Hertzian contact theory is used to calculate the contact force between the ball and the raceway over a long period, as shown in the following:

$$
Q=K \cdot \delta^{n}
$$

where $Q$ is the contact force, $K$ is the contact stiffness, $\delta$ is the contact deformation, and $n=1.5$ for a ball bearing.

The sinking depth of the ball in defect area is shown in Figure 1. The model in Figure 1(a) is the traditional model; [7-11, 15-17] used this model. However, all the sinking depths of the balls in Figure 1 are possible in the proposed model; the sinking depth is affected by the applied load.

In Figure 1(a), the sinking depth $\Delta$ of the ball is obtained from the width of the defect, as shown in the following:

$$
\Delta=r-\sqrt{r^{2}-L^{2}},
$$

where $r$ is the radius of the ball and $2 L$ is the width of the defect.

As mentioned previously, $\delta$ is the contact deformation between the ball and the raceways before the ball reaches the defect. When the ball passes over the defect, the remaining deformation between the ball and the raceways is $\delta-\Delta$; thus, according to (1), the ball-defect contact force is

$$
Q=K \cdot(\delta-\Delta)^{3 / 2}
$$




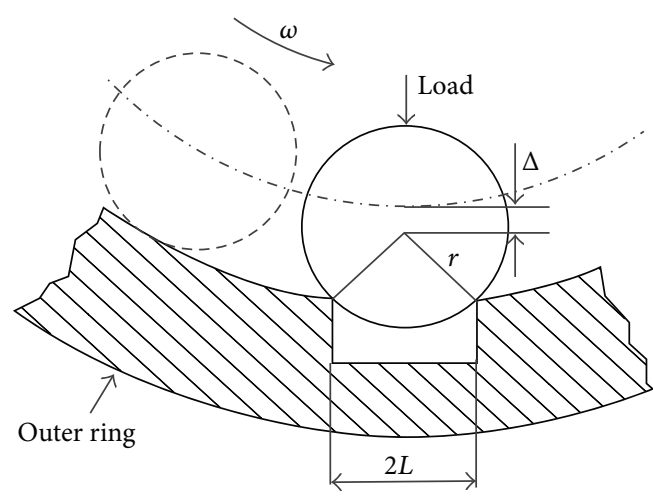

(a)

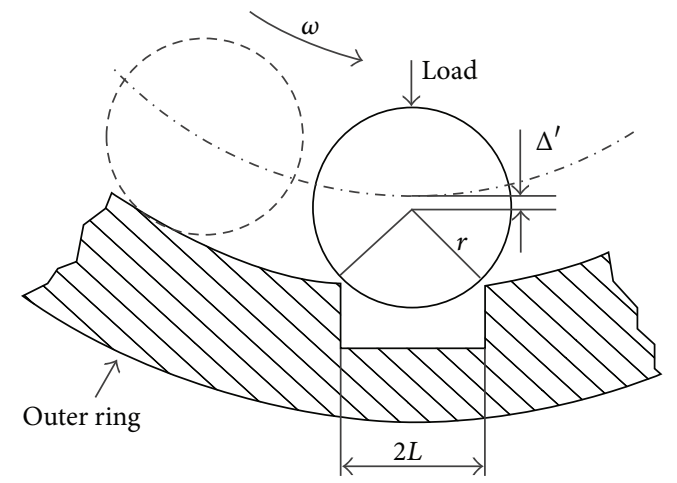

(b)

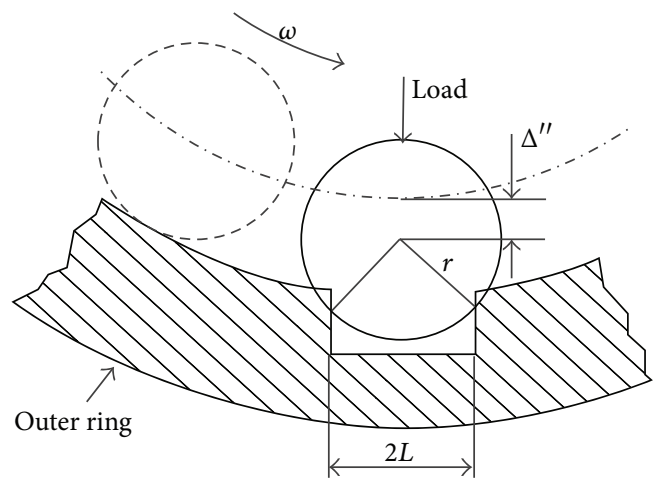

(c)

Figure 1: The sinking depth of the ball.

This method can be considered an approximate method. For details, refer to [11]. This traditional model has the following disadvantages.

(1) The sinking depth of the ball is a function of only the ball radius and the defect width, and it is independent of the applied load on the bearing. Moreover, after the sinking depth of the ball is determined, the path of the ball is also limited.

(2) When the ball contacts the raceways or the defect, a small contact area is simplified as a line contact or a point contact, which results in an inaccurate contact force.

To address these problems, a Hertzian contact stress distribution is applied to the calculation of the contact force in the defect area. In the proposed model, the sinking depth of the ball is related to the load applied on the bearing, and the contact area between the ball and defect is also considered.

\section{Bearing System Model}

3.1. Vibration Model of the Bearing. A vibration model of the bearing is presented in Figure 2. The ball bearing (Type 6204) is mounted at the end of a shaft. The inner ring is fixed rigidly to the motor shaft, and the outer ring is fixed to the housing. A constant additional load $F_{l}$ is applied to the housing in the vertical direction, and an accelerometer is mounted onto the housing to measure the vibration of the outer ring. The ball-raceway contact can be considered a spring-mass system. The proposed model incorporates the following realistic assumptions and considerations.
(1) The balls rotate with the cage; that is, the balls do not slip.

(2) The forces act in the radial direction only; the contact is an elastic contact and follows Hertzian contact theory.

(3) The forces act only in the radial plane of the bearing.

(4) When the ball passes over the localized defect on the raceway, the stress distribution between the ball and the raceway follows Hertzian contact theory.

(5) Because of the centrifugal force, the balls, cage, and outer ring have the same rotational frequencies.

(6) Grease is used in the bearing; the damping due to the lubricating film between the ball and the raceways and the damping of the shaft and the housing are considered.

3.2. Kinematics of the Balls. The inner and outer centres of the rolling element bearings are not concentric because of the applied load and the bearing clearance. Figure 3 illustrates the relationships between the motions of the components of the ball bearing, where $O_{\text {in }}\left(x_{i}, y_{i}\right)$ and $O_{\text {out }}\left(x_{o}, y_{o}\right)$ are the centres of the raceways, $P_{j}\left(p_{x, j}, p_{y, j}\right)$ is the centre of the $j$ th ball, the raceway radii are $R_{i}$ and $R_{o}$, the angular positions of the $j$ th ball on the raceways are $\alpha_{\mathrm{in}, j}$ and $\alpha_{\mathrm{out}, j}$, and $\alpha_{\mathrm{out}, j}$ can be described as follows:

$$
\alpha_{\text {out }, j}=2 \pi \cdot f_{c} \cdot t+\frac{\pi}{4}(j-1)+\alpha_{0} .
$$

In Figure 3 , the geometrical relationships of $\alpha_{\mathrm{in}, j}$ and $\alpha_{\text {out }, j}$ are as follows: 


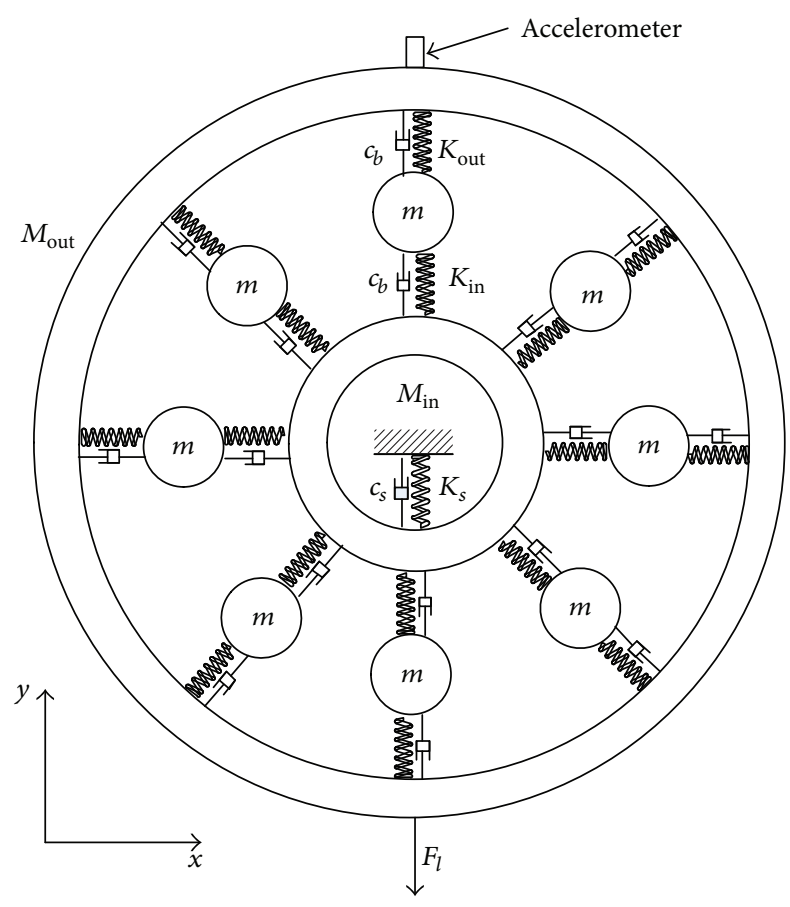

FIGURE 2: The bearing system model.

$$
\begin{aligned}
\cos \alpha_{\mathrm{in}, j}= & \frac{\left(x_{\mathrm{o}}+\mathrm{OP} P_{\mathrm{out}, j} \cdot \cos \alpha_{\mathrm{out}, j}-x_{i}\right)}{O P_{\mathrm{in}, j}} \\
\sin \alpha_{\mathrm{in}, j}= & \frac{\left(y_{\mathrm{o}}+O P_{\mathrm{out}, j} \cdot \sin \alpha_{\mathrm{out}, j}-y_{i}\right)}{O P_{\mathrm{in}, j}} \\
\cos \left(\alpha_{\mathrm{in}, j}-\alpha_{\mathrm{out}, j}\right)= & \cos \alpha_{\mathrm{in}, j} \cdot \cos \alpha_{\mathrm{out}, j}+\sin \alpha_{\mathrm{in}, j} \\
& \cdot \sin \alpha_{\mathrm{out}, j}
\end{aligned}
$$

where $f_{c}$ is the cage frequency, $\alpha_{0}$ is the initial angular position of the cage, $O P_{\mathrm{in}, j}=\sqrt{\left(p_{x, j}-x_{i}\right)^{2}+\left(p_{y, j}-y_{i}\right)^{2}}$, $O P_{\text {out }, j}=\sqrt{\left(p_{x, j}-x_{o}\right)^{2}+\left(p_{y, j}-y_{o}\right)^{2}}$, and the ball-raceway deformations are denoted as follows:

$$
\begin{gathered}
\delta_{\mathrm{in}, j}=r+R_{i}-O P_{\mathrm{in}, j}, \\
\delta_{\text {out }, j}=r-R_{o}-O P_{\text {out }, j} .
\end{gathered}
$$

\subsection{Defect Model Based on the Hertzian Contact Stress Distribution}

3.3.1. Hertzian Contact Stress Distribution. The analysis of the contact type of the bearing is presented below. In Figure 4, when a ball contacts the raceway, the contact is a point contact if the load is zero, as shown in Figure 4(a). After a load is applied to the ball, the contact point expands to an ellipse, as shown in Figure 4(b).

The Hertzian contact force calculation of a ball bearing was simplified. For the contact area between the ball and the raceway (both of which are made of steel), $a$ is the semimajor

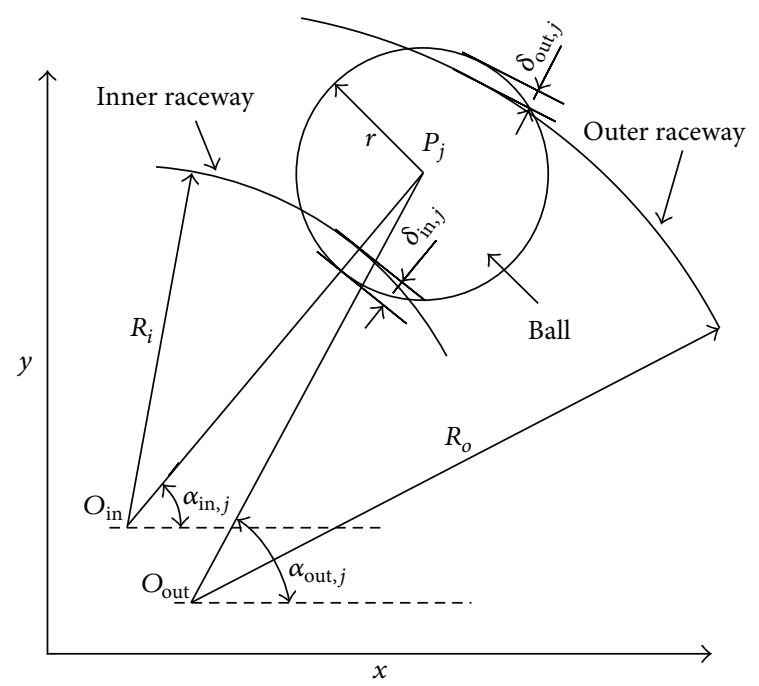

FIGURE 3: Relationships between the motions of the components of a ball bearing.

axis, and $b$ is the semiminor axis; they can be obtained as follows:

$$
\begin{aligned}
& a=0.0236 a^{*}\left(\frac{Q}{\sum \rho}\right)^{1 / 3}, \\
& b=0.0236 b^{*}\left(\frac{Q}{\sum \rho}\right)^{1 / 3},
\end{aligned}
$$

where $\sum \rho$ is the sum of the curvatures of the ball and the raceway and $a^{*}$ and $b^{*}$ can be obtained from [18].

The stress on the elliptical contact area is shown in Figure 5, and the normal stress within the contact area is given by the following:

$$
\sigma=\frac{3 Q}{2 \pi a b} \sqrt{1-\frac{x^{2}}{a^{2}}-\frac{y^{2}}{b^{2}}}
$$

3.3.2. Localized Defect Contact Force. When a ball passes over the localized defect (Figure 6), the shape of the ball-defect contact area changes as the ball moves. Figure 7 illustrates the geometry of the contact area in Figure 6 with coordinates, where the size of the localized defect is $2 L$; when the $j$ th ball moves from left to right, the contact area can be described as follows:

$$
\frac{x^{2}}{a^{2}}+\frac{\left(y-y_{j}\right)^{2}}{b^{2}}=1,
$$

where $y_{j}$ is the $y$-axis coordinate of the ellipse centre. According to (8) and (9), the compressive stress distribution of the contact ellipse is

$$
\sigma=\frac{3 Q}{2 \pi a b} \sqrt{1-\left(\frac{x}{a}\right)^{2}-\left(\frac{y-y_{j}}{b}\right)^{2}} .
$$

Figure 7 illustrates the variation of the ball-raceway contact area at the defect edge. As the ball begins to enter the 


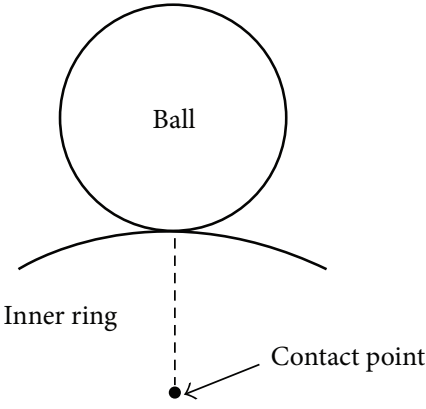

(a)

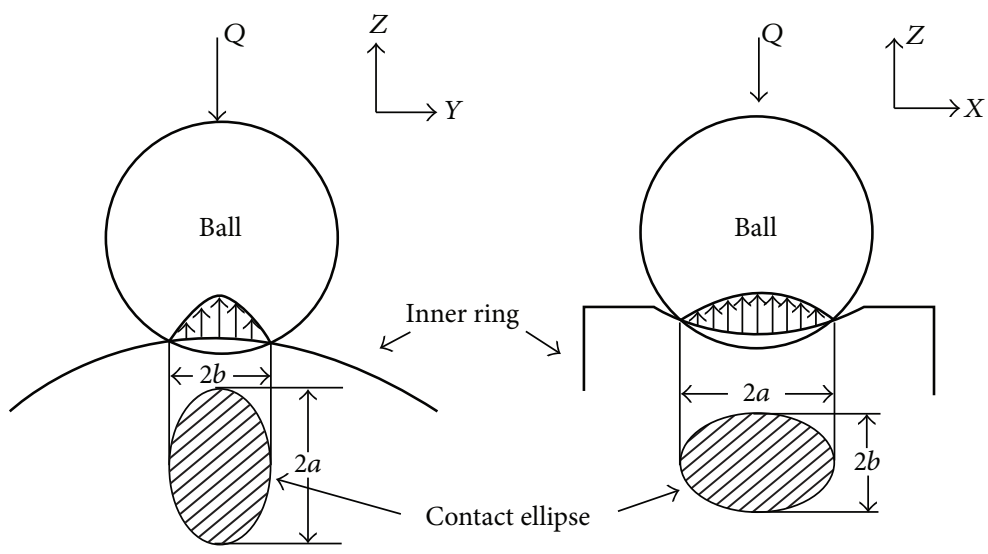

(b)

FiguRE 4: The contact area between the ball and raceway. (a) The contact point under no load conditions; (b) the contact ellipse under an applied load [18].

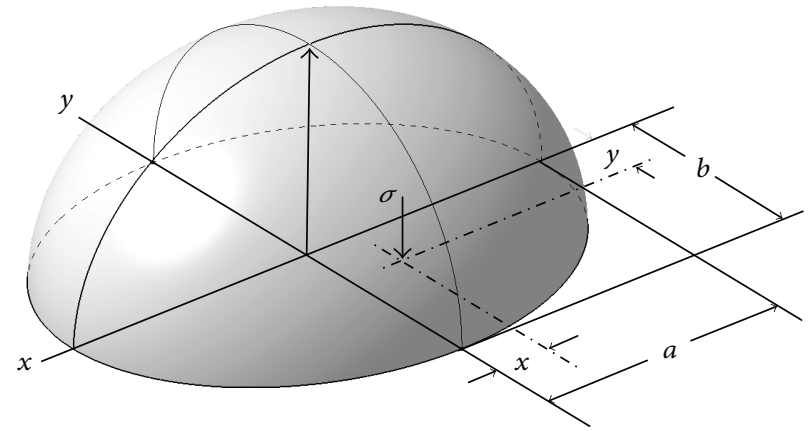

FIGURE 5: Compressive stress distribution of the ball-raceway contact.

defect (Figure 7(a)), the ball-raceway contact area at the left edge of the defect becomes smaller; at this stage, the range of $y_{j}$ is $-L-b \leq y_{j} \leq b-L$, and the contact force $Q_{j, f}$ between the $j$ th ball and the left edge of the defect (contact force of the shadow area) is

$$
\begin{aligned}
Q_{j, f}=\int_{y_{j}-b}^{-L} d y \int_{-a \sqrt{1-\left(\left(y-y_{j}\right) / b\right)^{2}}}^{a \sqrt{1-\left(\left(y-y_{j}\right) / b\right)^{2}}} \sigma d x, & \\
& -L-b \leq y_{j} \leq b-L .
\end{aligned}
$$

Figure 7(b) shows that there is no contact between the ball and the edge of the defect. When a ball enters the defect, if the contact force of the inner raceway is smaller, the speed of the bearing is faster, or the defect is larger, the sinking depth of the ball decreases, and the ball is unable to contact the edges of the defect. Thus, the contact force is zero. For this condition $(b<L)$, the contact force is

$$
Q_{j, f}=0, \quad b-L \leq y_{j} \leq L-b .
$$

Figure 7(c) shows that the ball is in contact with both edges of the defect; this condition is the opposite of that in Figure 7(b). For this condition $(b>L)$, the contact force is

$$
\begin{aligned}
Q_{j, f}= & \int_{y_{j}-b}^{-L} d y \int_{-a \sqrt{1-\left(\left(y-y_{j}\right) / b\right)^{2}}}^{a \sqrt{1-\left(\left(y-y_{j}\right) / b\right)^{2}}} \sigma d x \\
& +\int_{y_{j}+b}^{L} d y \int_{-a \sqrt{1-\left(\left(y-y_{j}\right) / b\right)^{2}}}^{a \sqrt{1-\left(\left(y-y_{j}\right) / b\right)^{2}}} \sigma d x, \\
& L-b \leq y_{j} \leq b-L .
\end{aligned}
$$

In Figure $7(\mathrm{~d})$, as the ball exits the defect, the contact area becomes larger, the range of $y_{j}$ is $L-b \leq y_{j} \leq L+b$, and the contact force between the ball and the right edge of the defect is

$$
\begin{aligned}
Q_{j, f}=\int_{y_{j}+b}^{L} d y \int_{-a \sqrt{1-\left(\left(y-y_{j}\right) / b\right)^{2}}}^{a \sqrt{1-\left(\left(y-y_{j}\right) / b\right)^{2}}} \sigma d x, & \\
& L-b \leq y_{j} \leq L+b .
\end{aligned}
$$

For the ball bearing with a localized defect on the raceway, the centre of the contact ellipse is $y_{j}$, its angular position on the outer raceway is equal to the angular position of the ball centre, and the angular position of the defect on the outer raceway is $\alpha_{\text {out }, f}$. When the ball moves near the defect, the relationship between $y_{j}$ and $\alpha_{\mathrm{out}, f}$ is as follows: 


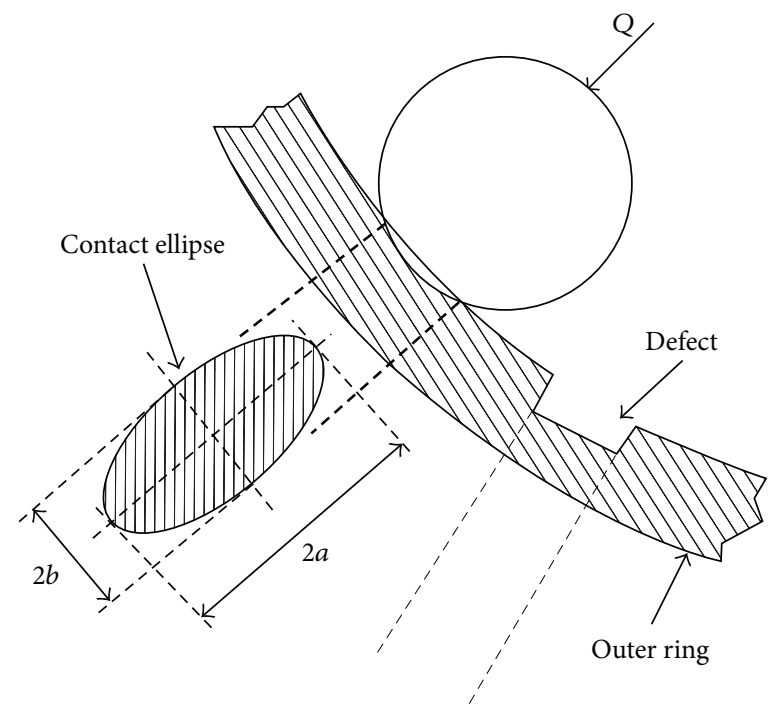

FIgURE 6: The ball-raceway contact area and a defect on the outer ring.

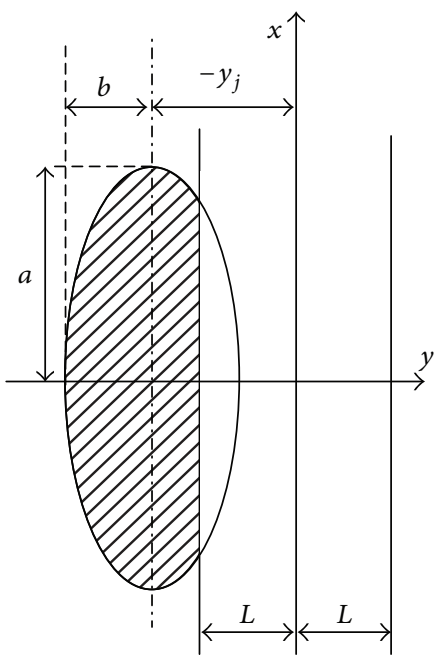

(a)

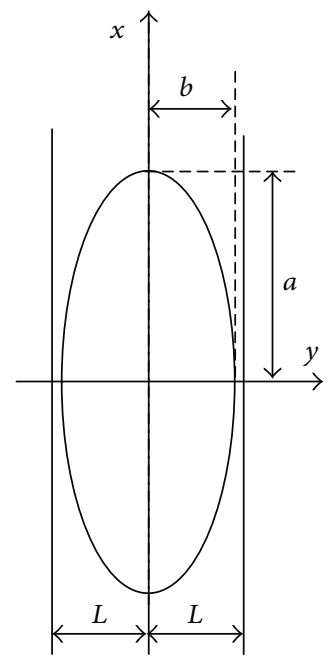

(b)

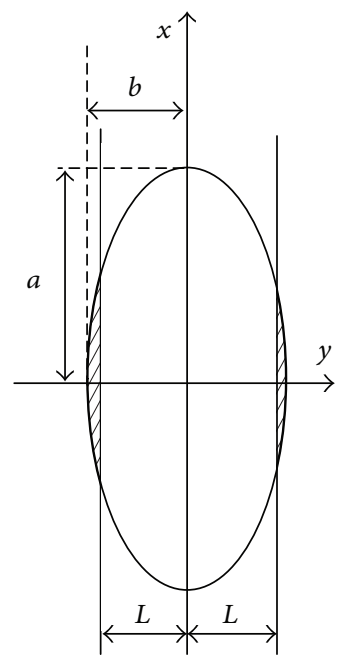

(c)

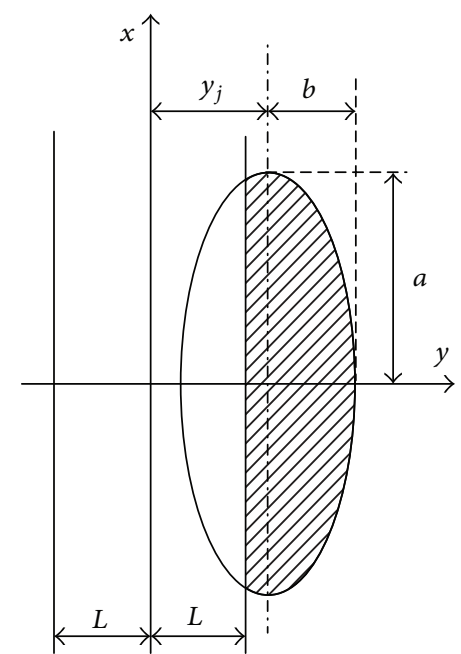

(d)

FIGURE 7: The variation of the ball-raceway contact area at the defect edge.

$$
\alpha_{\text {out }, j}=\alpha_{\text {out }, f}+\frac{y_{j}}{R_{o}}, \quad y_{j} \ll R_{o} .
$$

3.4. Calculation of the Contact Force. The contact forces between the $j$ th ball and the raceways are given by $Q_{i n, j}$ and $Q_{\text {out }, j}$ :

$$
\begin{gathered}
Q_{\text {out }, j}=K_{\text {out }} \delta_{\text {out }}^{3 / 2}, \\
Q_{\text {in }, j}=K_{\text {in }} \delta_{\text {in }}^{3 / 2} .
\end{gathered}
$$

When a ball passes the defect, the contact force between the ball and the outer raceway in the defect area is given by

$$
\begin{gathered}
Q_{\mathrm{out}, j}=Q_{j, f}, \\
\alpha_{\mathrm{out}, f}-\frac{(L+b)}{R_{o}} \leq \alpha_{\mathrm{out}, j} \leq \alpha_{\mathrm{out}, f}+\frac{(L+b)}{R_{o}} .
\end{gathered}
$$

The sums of the contact forces between the balls and the raceways in the $x$-axis and $y$-axis directions are as follows:

$$
\begin{gathered}
Q_{\mathrm{in}, y}=\sum_{j=1}^{n} Q_{\mathrm{in}, j} \cdot \sin \alpha_{\mathrm{in}, j}, \\
Q_{\mathrm{in}, x}=\sum_{j=1}^{n} Q_{\mathrm{in}, j} \cdot \cos \alpha_{\mathrm{in}, j}, \\
Q_{\text {out } y}=\sum_{j=1}^{n} Q_{\text {out }, j} \cdot \sin \alpha_{\text {out }, j}, \\
Q_{\text {out }, x}=\sum_{j=1}^{n} Q_{\text {out }, j} \cdot \cos \alpha_{\text {out }, j} \cdot
\end{gathered}
$$


3.5. Damping. The damping coefficient $c_{b}$ of the balls resulting from the built-up oil film during rotation is as follows [19]:

$$
0.25 \times 10^{-5} \times K_{\text {lin }} \leq c_{b} \leq 2.5 \times 10^{-5} \times K_{\text {lin }} .
$$

The shaft and housing damping coefficients are calculated using the following [20]:

$$
c_{s}=\frac{\mathrm{LF} \cdot K_{s}}{\omega_{\mathrm{ext}}},
$$

where $K_{\text {lin }}$ is the linear stiffness of the bearing, the loss factor LF depends on the material, $\omega_{\text {ext }}$ is the excitation frequency, and $K_{s}$ is the stiffness of the support shaft, which can be calculated by the finite element software ANSYS. The values of the parameters in (19) and (20) are $K_{\operatorname{lin}}=3.34 \times 10^{4} \mathrm{~N} / \mathrm{mm}$, $\mathrm{LF}=0.01, K_{s}=3.70 \times 10^{4} \mathrm{~N} / \mathrm{mm}$, and $\omega_{\text {ext }}=30$.

The damping forces between $j$ th ball and the raceways can be expressed as $F_{d, \text { in }, j}=c_{b} \cdot \dot{\delta}_{\text {in, } j}$ and $F_{d, \text { out }, j}=c_{b} \cdot \dot{\delta}_{\text {out }, j}$, and the total contact damping forces acting on the inner and outer raceways in the $x$-axis and $y$-axis directions are given by

$$
\begin{gathered}
F_{d, \mathrm{in}, x}=\sum_{j=1}^{n} F_{d, \mathrm{in}, j} \cdot \cos \alpha_{\mathrm{in}, j}, \\
F_{d, \mathrm{out}, x}=\sum_{j=1}^{n} F_{d, \mathrm{out}, j} \cdot \cos \alpha_{\mathrm{out}, j}, \\
F_{d, \mathrm{in}, y}=\sum_{j=1}^{n} F_{d, \mathrm{in}, j} \cdot \sin \alpha_{\mathrm{in}, j}, \\
F_{d, \mathrm{out}, y}=\sum_{j=1}^{n} F_{d, \mathrm{out}, j} \cdot \sin \alpha_{\mathrm{out}, j} .
\end{gathered}
$$

3.6. Vibration Equations of the Bearings. According to the bearing system model shown in Figure 2, the vibration equations for the inner and outer rings of the ball bearing in the $x$-axis and $y$-axis directions are as follows:

$$
\begin{aligned}
& M_{\mathrm{in}} \cdot \ddot{y}_{\mathrm{in}}+c_{s} \cdot \dot{y}_{\mathrm{in}}+K_{s} \cdot y_{\mathrm{in}}+Q_{\mathrm{in}, y}+F_{d, \mathrm{in}, y} \\
& \quad=-M_{\mathrm{in}} g, \\
& M_{\mathrm{in}} \cdot \ddot{x}_{\mathrm{in}}+c_{s} \cdot \dot{x}_{\mathrm{in}}+K_{s} \cdot x_{\mathrm{in}}+Q_{\mathrm{in}, x}+F_{d, \mathrm{in}, x}=0, \\
& M_{\text {out }} \cdot \ddot{x}_{\text {out }}+F_{d, \text { out }, x}-Q_{\text {out }, x}=0, \\
& M_{\text {out }} \cdot \ddot{y}_{\text {out }}+F_{d, \text { out }, y}-Q_{\text {out }, y}=-M_{\text {out }} g-F_{l},
\end{aligned}
$$

where $M_{\text {in }}$ is the mass of the inner ring and shaft, $M_{\text {out }}$ is the mass of the outer ring and housing, and $F_{l}$ is the gravitational load. The vibration equation of the $j$ th ball in the outer ring's radial direction is given by

$$
\begin{aligned}
m & \cdot \ddot{\delta}_{\text {out }, j}+F_{d, \text { out }, j}+F_{d, \text { in }, j} \cdot \cos \left(\alpha_{\mathrm{in}, j}-\alpha_{\text {out }, j}\right) \\
& =-Q_{\text {out }, j}+Q_{\text {in }, j} \cdot \cos \left(\alpha_{\text {in }, j}-\alpha_{\text {out }, j}\right)-m \omega^{2} r,
\end{aligned}
$$

where $\omega=2 \pi f_{c}$, the initial coordinates, velocities, and acceleration of the raceways and balls are set to reasonable
TABLE 1: Parameters of the type 6204 bearing.

\begin{tabular}{lc}
\hline Inner groove radius & $4.088 \mathrm{~mm}$ \\
Outer groove radius & $4.168 \mathrm{~mm}$ \\
Inner raceway radius & $13.281 \mathrm{~mm}$ \\
Outer raceway radius & $21.226 \mathrm{~mm}$ \\
Number of balls & 8 \\
Ball radius & $3.969 \mathrm{~mm}$ \\
Radial clearance & $3.25 \mathrm{um}$ \\
\hline
\end{tabular}

values, and the angular positions of the balls vary according to (4). The fourth-order Runge-Kutta algorithm is used to solve (22) and (23) with the commercial software MATLAB to calculate the motion parameters of each component. The damping and stiffness values in the numerical model are given as follows: $c_{s}=0.74 \mathrm{Ns} / \mathrm{mm}, c_{b}=0.8 \mathrm{Ns} / \mathrm{mm}, K_{i}=8.98$ $\times 10^{5} \mathrm{~N} / \mathrm{mm}^{3 / 2}$, and $K_{o}=8.98 \times 10^{5} \mathrm{~N} / \mathrm{mm}^{3 / 2}$. The flow chart of the numerical computation is shown in Figure 8.

\section{Experimental Setup}

The experimental rig and the bearing (Type 6204) are shown in Figure 9. The mass of the housing is $1.345 \mathrm{~kg}$; additional loads of $4.9 \mathrm{~N}, 9.8 \mathrm{~N}, 14.7 \mathrm{~N}$, and $19.6 \mathrm{~N}$ are applied to the housing in the vertical direction. When a ball passes over the defect on the outer raceway, the periodic vibration response is recorded by the acceleration sensor above the bearing housing. The experimental vibration signals and the numerical signals are analysed by the resonance demodulation method, which is used to diagnose early fault defects of rolling bearings; [21] introduces the theory of this method in detail.

The type 6204 bearing shown in Figure 9(b) has a localized defect on the outer raceway. The defect is $0.2 \mathrm{~mm}$ wide, $14.0 \mathrm{~mm}$ long, and $1.0 \mathrm{~mm}$ deep, and it is located vertically in the loaded region. The rotational frequency of the bearing is $1800 \mathrm{rpm}$. The bearing parameters are given in Table 1.

\section{Experimental and Numerical Results}

5.1. Comparison between Experimental Signals and Numerical Signals. Figure 10 shows the vibration responses of the experimental and numerical signals under the different load conditions. The results show that, with an increase of the additional load, the amplitude of the vibration signals increases; because the bearing has a random vibration, the vibration amplitude of the numerical signals coincides somewhat with the mean vibration amplitude of the experimental signals.

Figure 11 shows the frequency spectra of the experimental and numerical signals under the different load conditions. For the ball bearing with a localized defect on the outer raceway, the theoretical fault characteristic frequency (ball pass frequency for the outer race) is $92.39 \mathrm{~Hz}$. The vibration amplitude and frequency of the fault signals are given in Table 2. The fault characteristic frequencies of the 


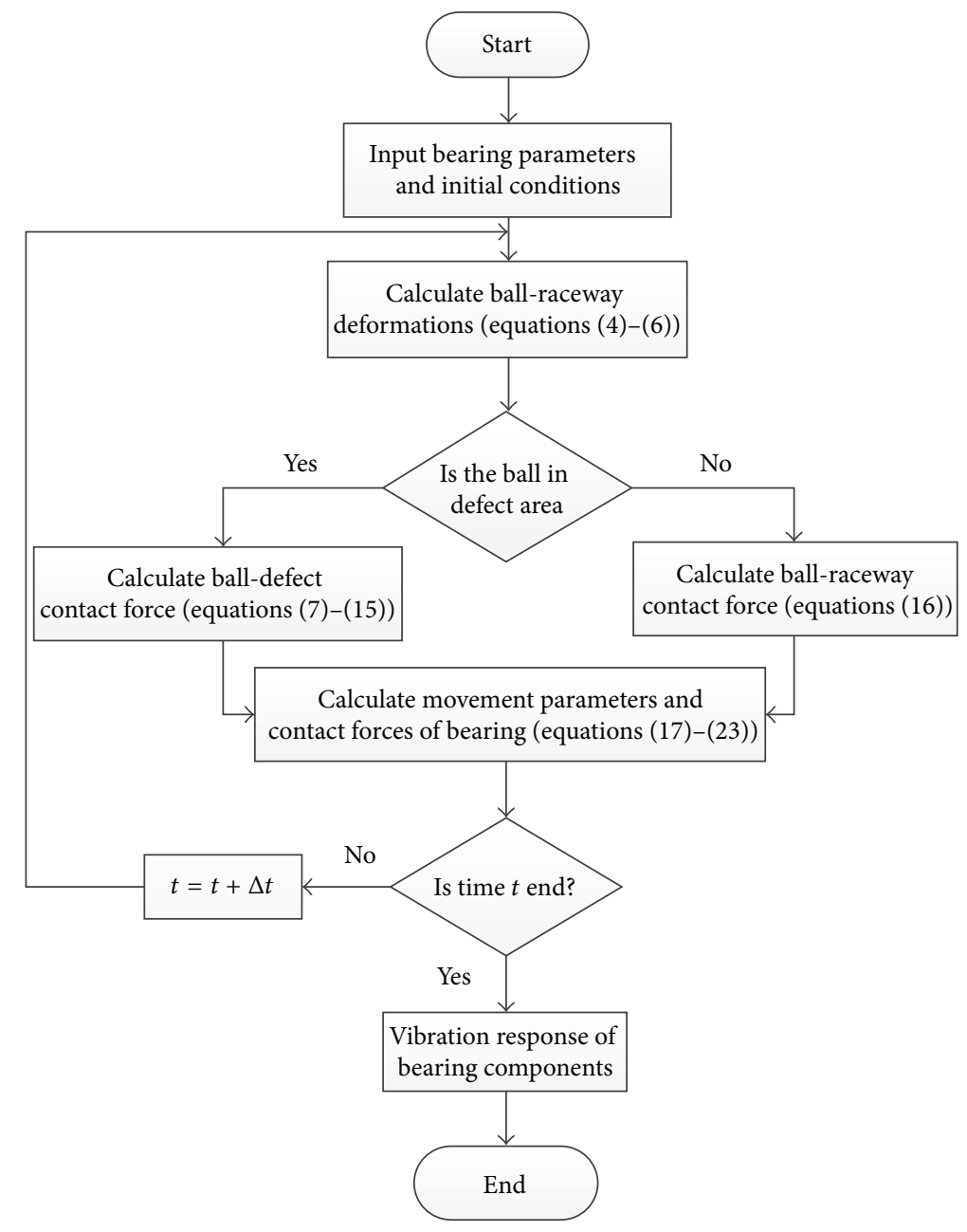

FIGURE 8: Flow chart of the numerical computation.

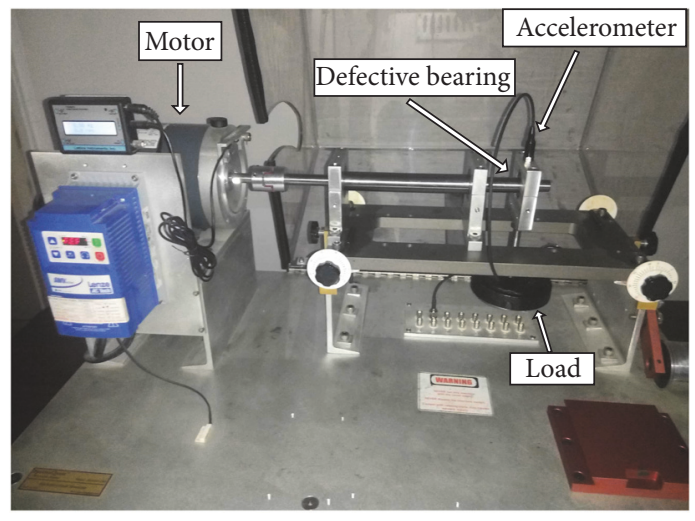

(a) Experimental rig

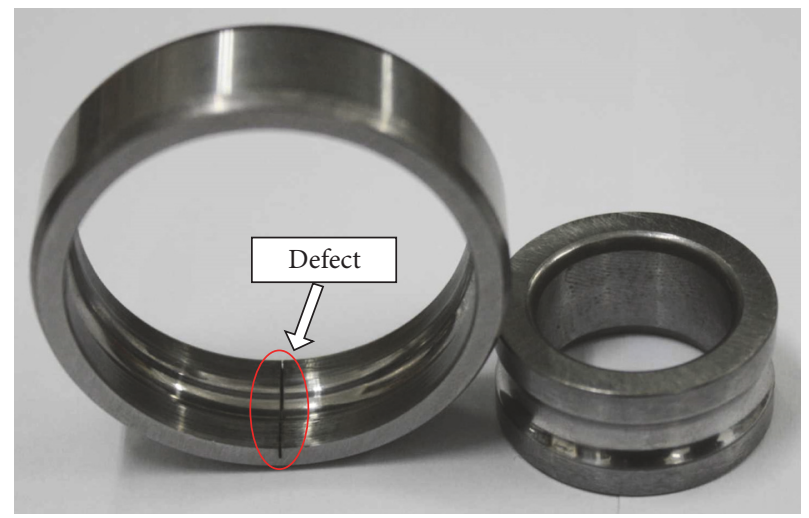

(b) Localized defect on the outer raceway

Figure 9

experimental signals and the numerical signals are consistent and are very similar to the theoretical fault characteristic frequency. The vibration amplitudes of the experimental and numerical signals both increase with increases of the additional load because a greater load will cause the impact forces between the balls and the defect to increase, which will increase the vibration amplitudes of the signals. In addition, the vibration amplitudes of the numerical signals are slightly greater than those of the experimental signals. The defect's surface morphology may have an effect on the distribution of 


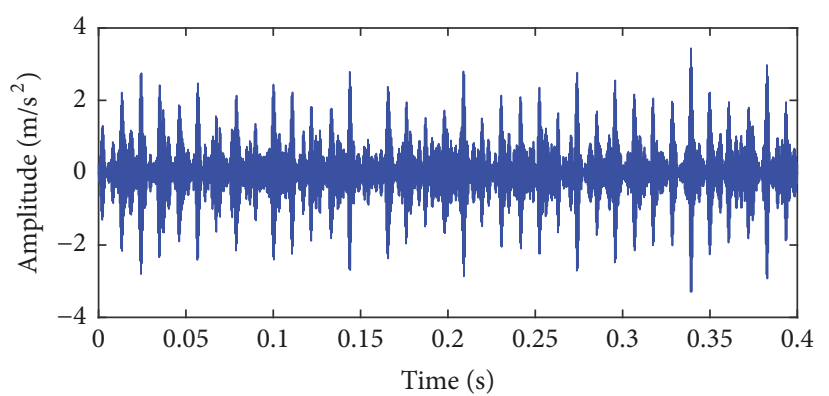

(a)

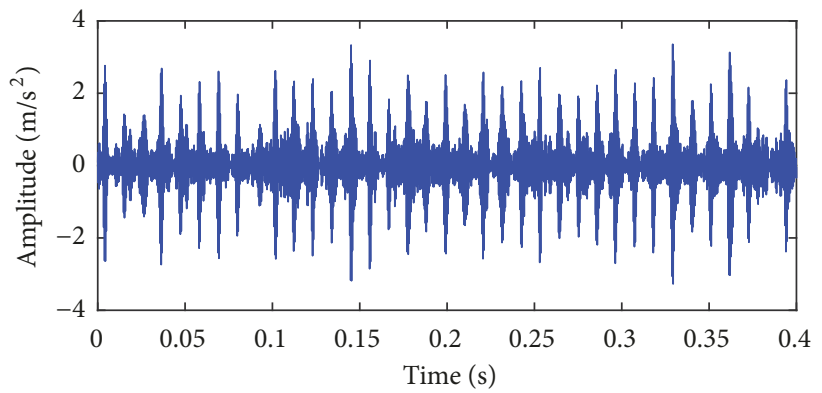

(b)

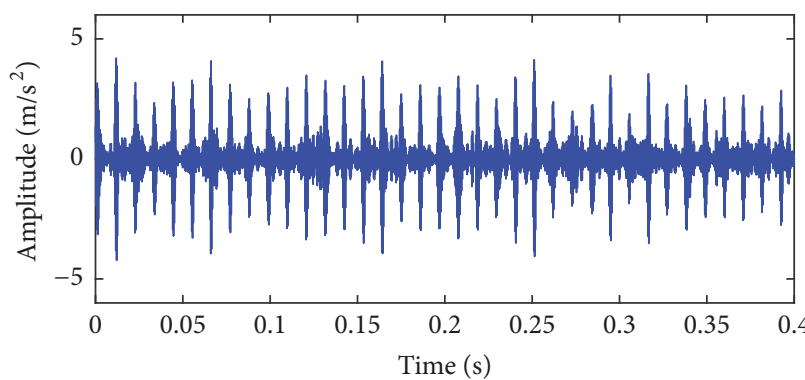

(c)

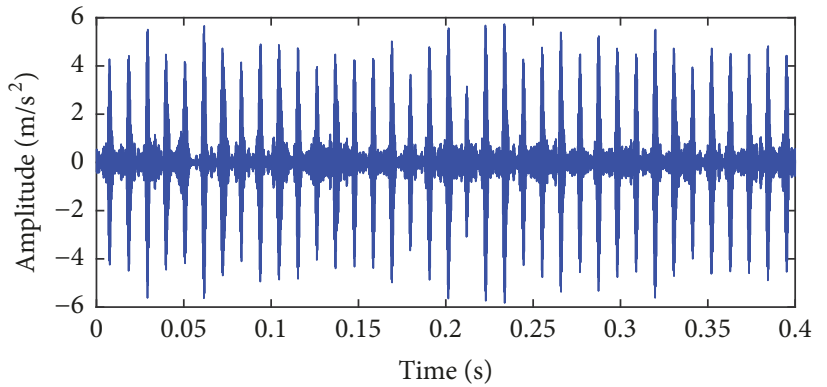

(d)

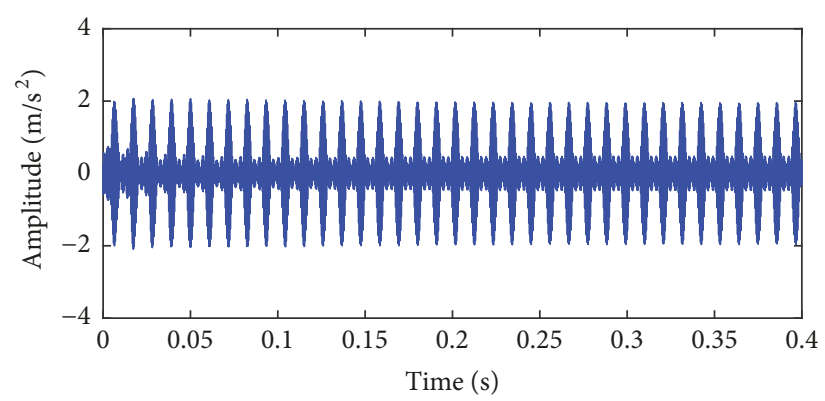

(e)

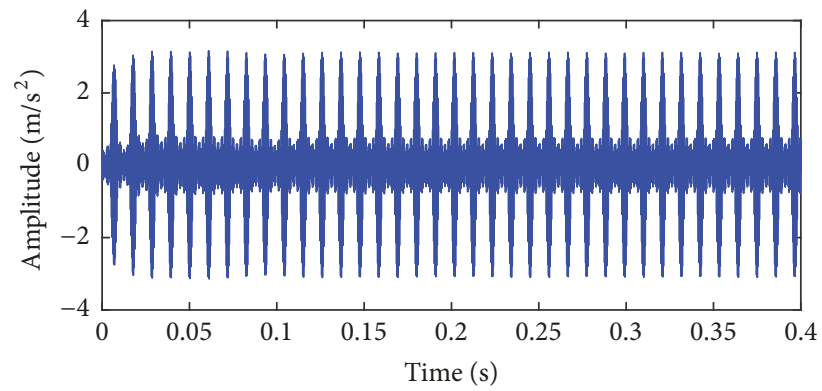

(f)

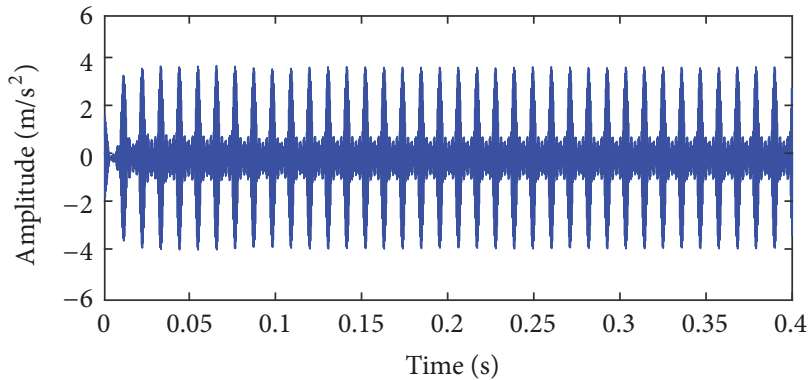

(g)

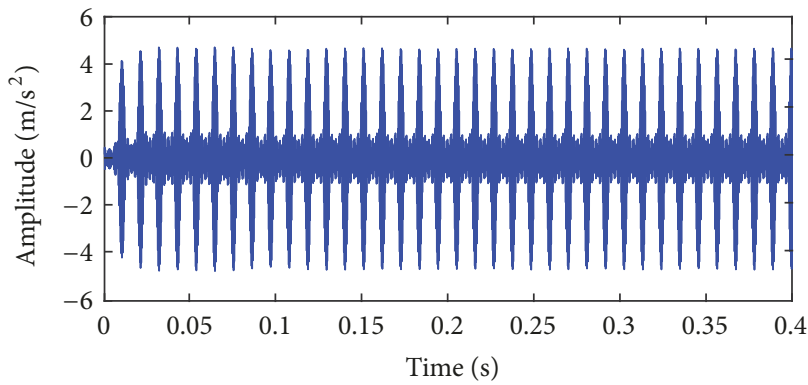

(h)

FIGURE 10: Vibration responses of the experimental signals and the numerical signals under different loads. Experimental signals: (a) $4.9 \mathrm{~N}$, (b) $9.8 \mathrm{~N},(\mathrm{c}) 14.7 \mathrm{~N}$, and (d) $19.6 \mathrm{~N}$. Numerical signals: (e) $4.9 \mathrm{~N}$, (f) $9.8 \mathrm{~N}$, (g) $14.7 \mathrm{~N}$, and (h) $19.6 \mathrm{~N}$.

TABLE 2: Comparison of the fault signals in Figure 11.

\begin{tabular}{|c|c|c|c|c|}
\hline \multirow{2}{*}{ Load $(\mathrm{N})$} & \multicolumn{2}{|c|}{ Numerical signals } & \multicolumn{2}{|c|}{ Experimental signals } \\
\hline & Frequency $(\mathrm{Hz})$ & Amplitude $\left(\mathrm{m} / \mathrm{s}^{2}\right)$ & Frequency $(\mathrm{Hz})$ & Amplitude $\left(\mathrm{m} / \mathrm{s}^{2}\right)$ \\
\hline 4.9 & 92.19 & 85.92 & 92.19 & 60.49 \\
\hline 9.8 & 92.19 & 119.7 & 92.19 & 74.69 \\
\hline 14.7 & 92.19 & 150.1 & 92.19 & 93.74 \\
\hline 19.6 & 92.19 & 184.9 & 92.97 & 169.4 \\
\hline
\end{tabular}




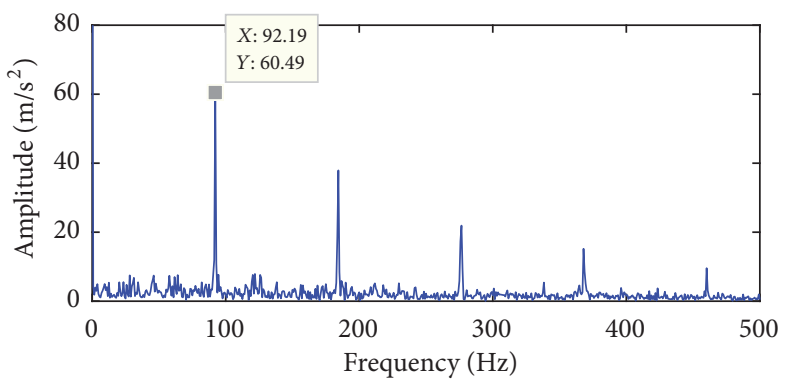

(a)

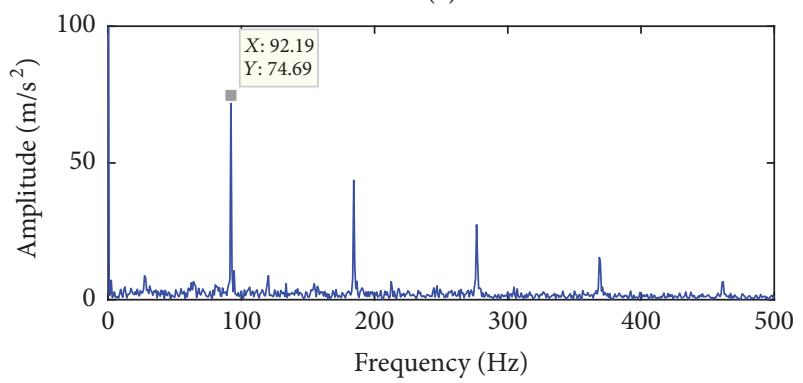

(b)

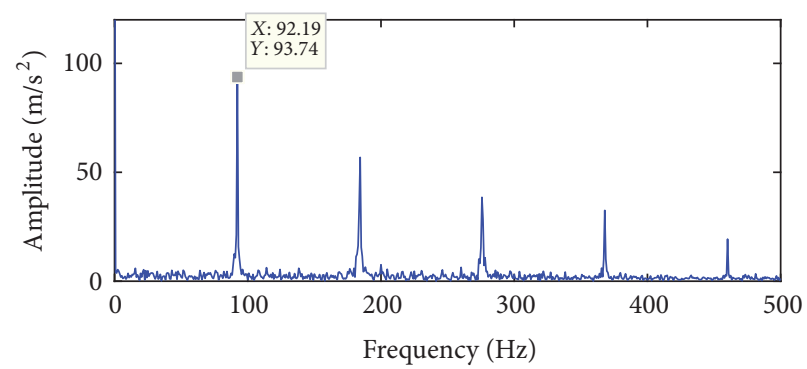

(c)

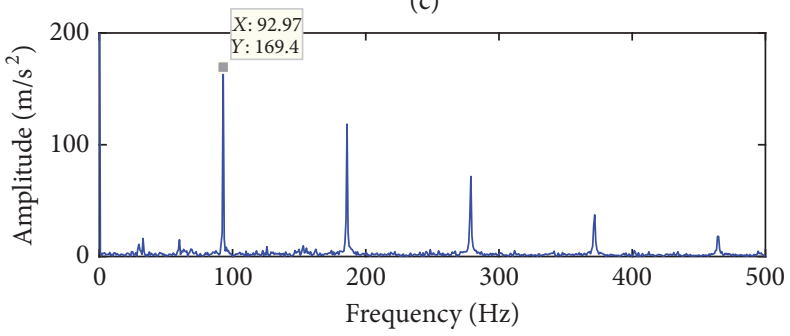

(d)

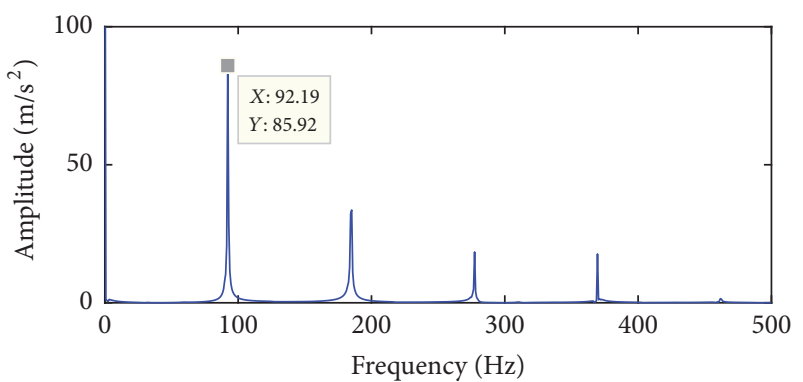

(e)
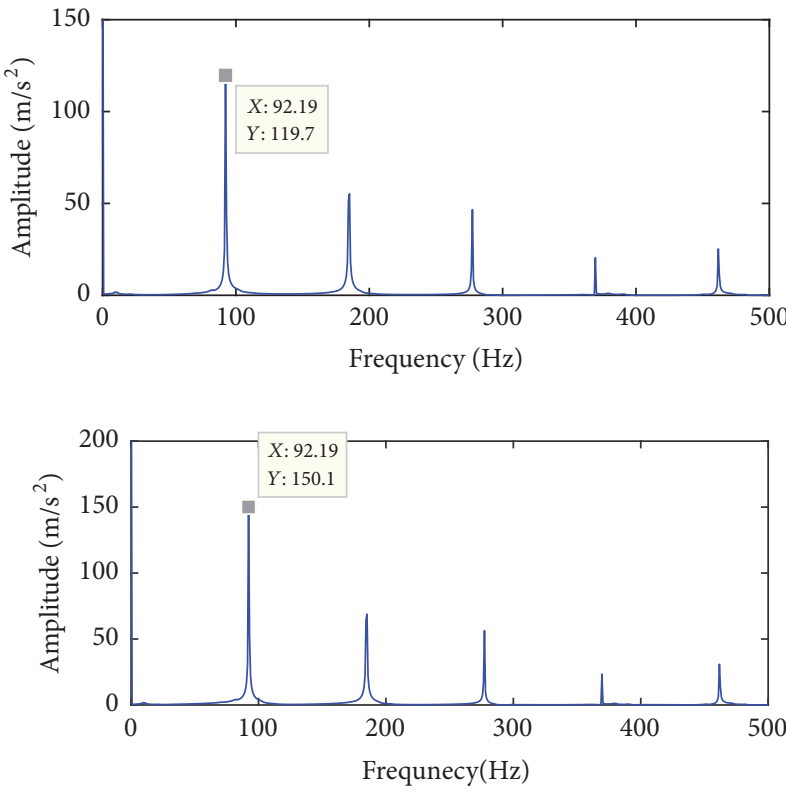

(g)

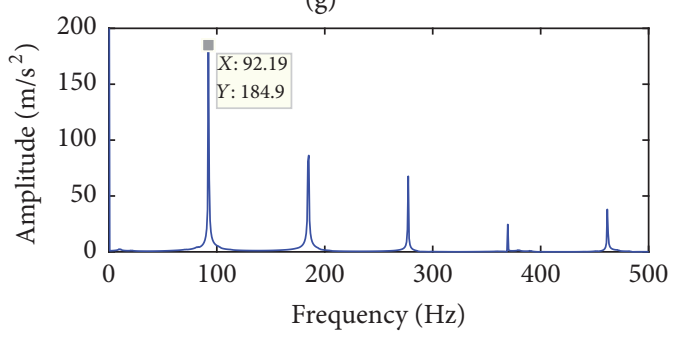

(h)

FIGURE 11: Frequency spectra of the experimental signals and the numerical signals under different loads. Experimental signals: (a) $4.9 \mathrm{~N}$, (b) $9.8 \mathrm{~N},(\mathrm{c}) 14.7 \mathrm{~N}$, and (d) $19.6 \mathrm{~N}$. Numerical signals: (e) $4.9 \mathrm{~N}$, (f) $9.8 \mathrm{~N}$, (g) $14.7 \mathrm{~N}$, and (h) $19.6 \mathrm{~N}$.

the contact stress and the shape of the contact area; this effect will be studied in future articles.

\subsection{Comparison between the Proposed Model and the Traditional Model}

5.2.1. Sinking Depth of the Balls. In contrast to the traditional model, which only considers the effect of the defect size on the sinking depth of balls in the defect area, the model proposed in this paper considers both the defect size and the load. Figure 12 shows the relationships among the maximum sinking depth of the balls, the size of the defect, and the load for the traditional model and the proposed model. The sinking depth of the ball in the traditional model is independent of the load, whereas, in the proposed model, the maximum sinking depth increases with increases of the load and the size of the defect.

The paths of the balls passing through the defect area under different loads calculated with the proposed model are shown in Figure 13. The sinking depths of the balls increase with increasing load. The sinking depths of the balls shown in Figure 13 are listed in Table 3; the trend is consistent with that in Figure 12(b) because a greater applied load causes greater acceleration and velocity of the balls, as shown in Figures 14 and 15 .

Table 4 shows the relationships between the contact ellipse and the sinking depth of the ball. In Figure 13, the sinking depth of the ball ranges between $0.8 \times 10^{-3} \mathrm{~mm}$ and 
TABLE 3: Relationship between the additional load and the change of the sinking depth of the balls in Figure 13.

\begin{tabular}{lcr}
\hline Additional load $(\mathrm{N})$ & Change of sinking depth $\Delta\left(10^{-3} \mathrm{~mm}\right)$ & 0.70 \\
\hline 4.9 & & 0.80 \\
9.8 & 1.26 & 0.91 \\
14.7 & & 1.02 \\
19.6 & & Praditional model \\
\hline
\end{tabular}

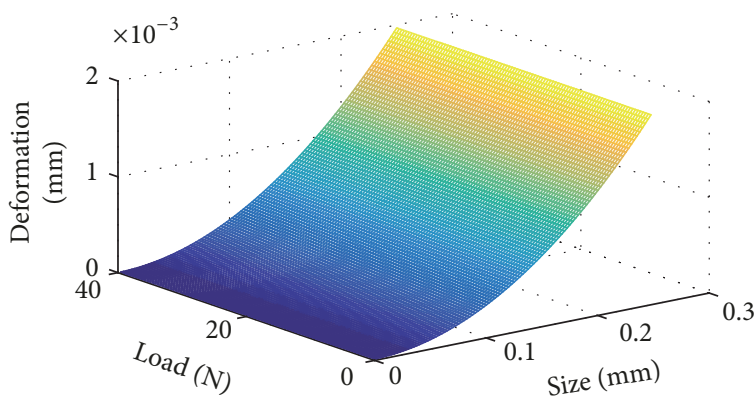

(a) Traditional model

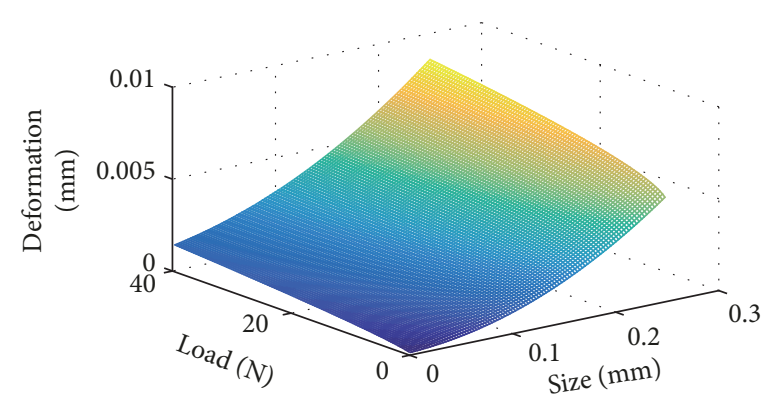

(b) Proposed model

Figure 12: Maximum sinking depth of the balls at the centre of the defect.

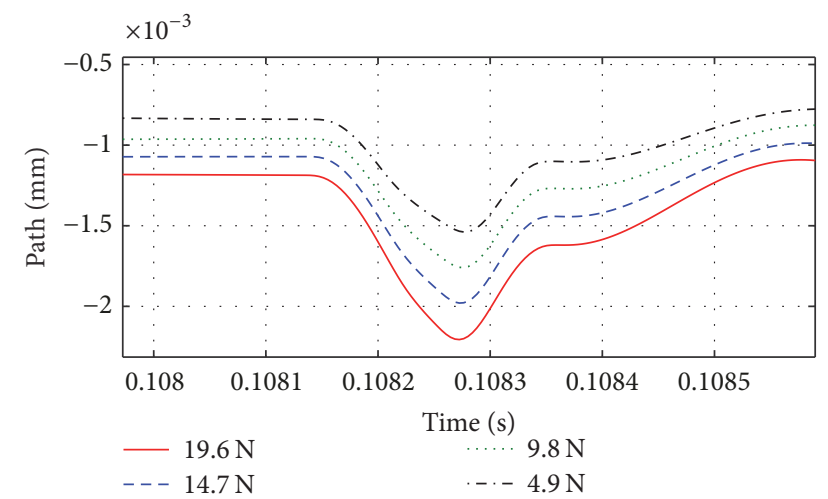

Figure 13: Paths of the balls passing through the defect area under different loads.

$2.2 \times 10^{-3} \mathrm{~mm}$; the values of the semimajor and semiminor axes of the contact ellipse based on this range are given in Table 4 . When the sinking depth of the ball is $0.8 \times 10^{-3} \mathrm{~mm}$, the ball does not enter the defect; at this stage, the semiminor axis of the contact area is $0.0485 \times 2=0.097 \mathrm{~mm}$, and the width of the defect is $0.2 \mathrm{~mm}$. The size of the contact ellipse is clearly nonnegligible because the ball-raceway contact force was affected by the defect before the ball enters the defect.

When the sinking depth of the ball is $2.2 \times 10^{-3} \mathrm{~mm}$, the semiminor axis of the contact area is $0.0805 \times 2=0.1610 \mathrm{~mm}$, which is smaller than the width of the defect, so there is no contact between the ball and the defect edges when the ball is in the centre of the defect; at this stage, contact force between the ball and the outer raceway is zero. The ball has left the defect area on the outer raceway before it reaches the maximum sinking depth $6 \times 10^{-3} \mathrm{~mm}$.
In general, the sinking depth in Figure $12(\mathrm{~b})$ is the maximum sinking depth when the ball stays at the defect area. In Figure 13, the ball has a velocity when it passes through the defect area, the movement of the ball will affect the paths of the balls.

5.2.2. Contact Force. The ball-raceway contact forces of the traditional and proposed models in the defect area under different loads are shown in Figure 16. In the traditional model, the contact force changes suddenly when the ball enters and leaves the defect area, whereas there is a continuous and gradual change in the proposed model. The traditional model presented in this paper is only a basic model; the contact forces of the traditional models in $[11,12]$ also have nonabrupt changes. We do not compare the differences between the changing processes of the contact forces in the proposed model and the traditional models. Whether the traditional model or the proposed model is used, the change of the contact forces increases with an increase in the applied load. There are two other differences between these two models.

(1) The duration of the change in the contact force in the defect area in the proposed model is greater than that in the traditional models.

(2) The change of the contact force in the traditional model is smaller than that in the proposed model; when the ball is at the centre of the defect, the contact force between the ball and the raceway is zero in the new model.

The reasons for these differences are as follows.

(1) The traditional model neglects the contact areas between the ball and the raceways; a change occurs only when the centre of the ball enters the defect.

(2) When the minor axis of the contact ellipse is smaller than the size of the defect, the ball cannot come into contact with the raceway when it passes over the defect; thus, the contact force becomes zero. 


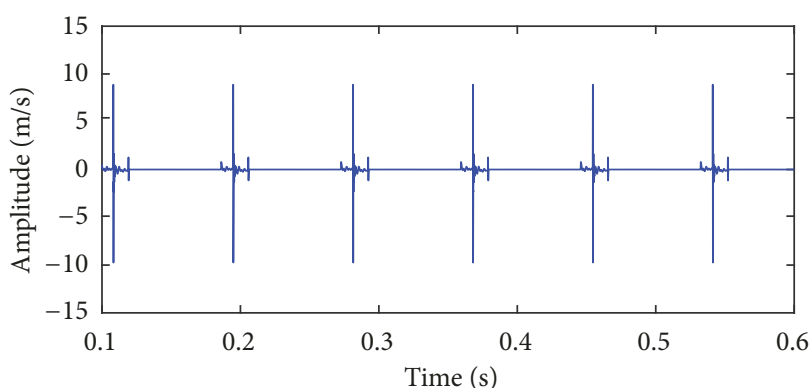

(a)

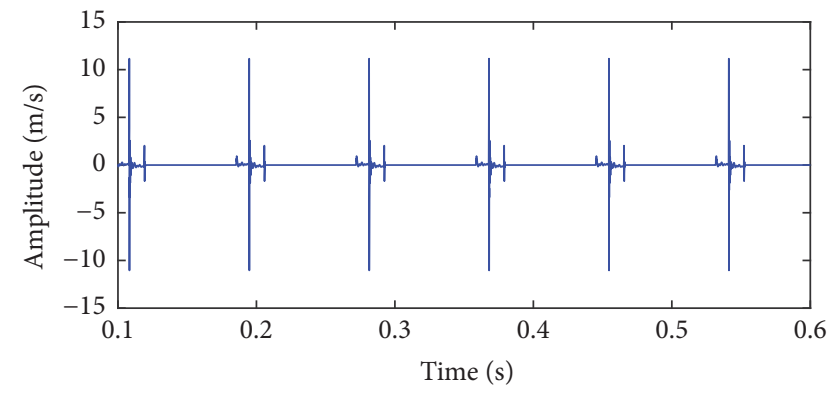

(c)

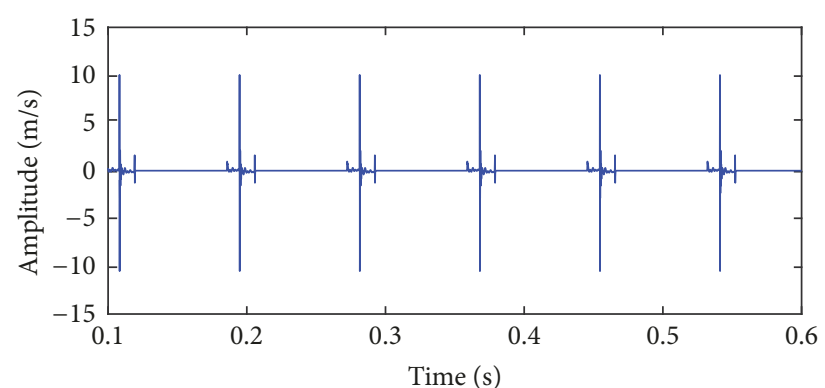

(b)

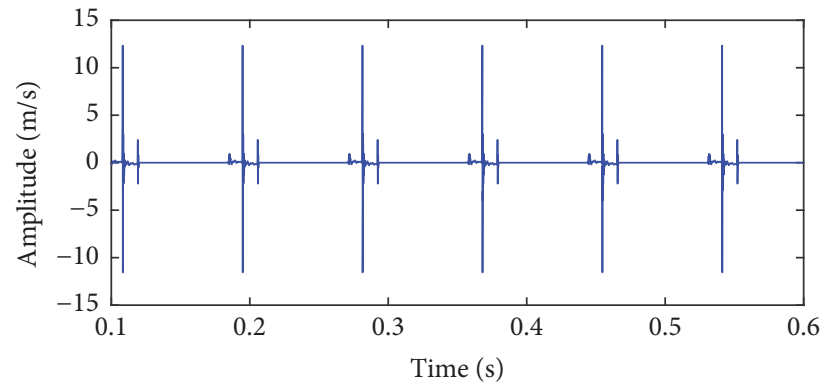

(d)

FIGURE 14: Velocities of the balls in the radial direction in the defect area under different loads: (a) $4.9 \mathrm{~N}$, (b) $9.8 \mathrm{~N}$, (c) $14.7 \mathrm{~N}$, and (d) $19.6 \mathrm{~N}$.

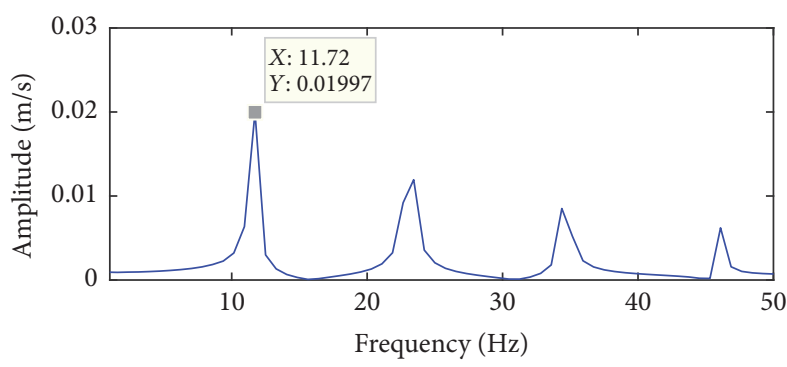

(a)

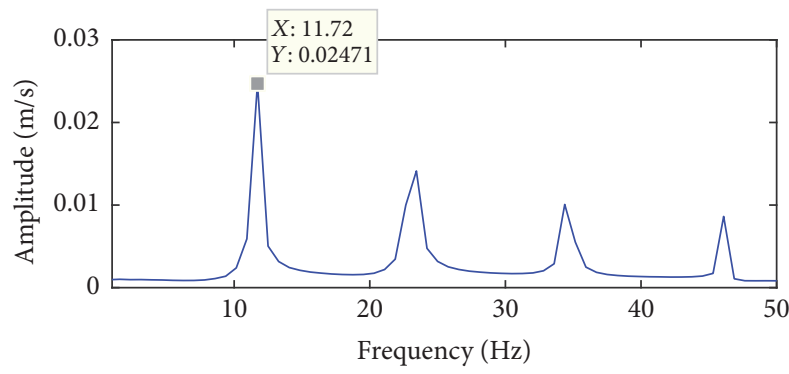

(c)

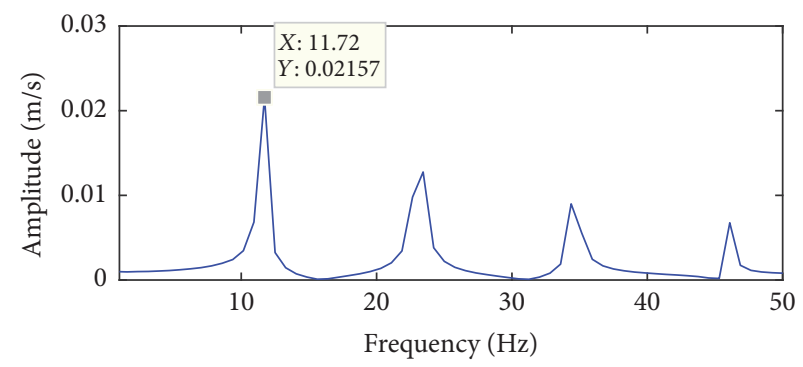

(b)

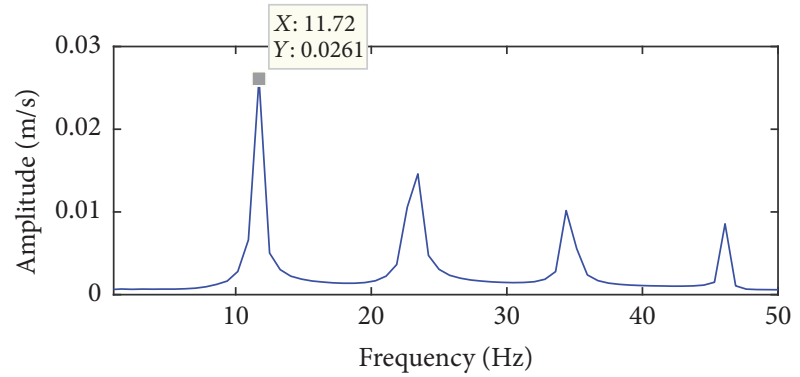

(d)

FiguRE 15: The spectra of velocities of the balls in the radial direction in the defect area under different loads: (a) $4.9 \mathrm{~N}$, (b) $9.8 \mathrm{~N}$, (c) $14.7 \mathrm{~N}$, and (d) $19.6 \mathrm{~N}$.

In Figure 16(a), the duration of the change in the contact force is the time required for the ball to pass over the defect. The width of the defect is $2 L$, and the velocity of the ball is $2 \pi f_{c} R_{o}$; therefore, the duration of the change in the contact force in the defect area is $L / \pi f_{c} R_{o}$. For the experiment in this article, the duration is $1.298 \times 10^{-4} \mathrm{~s}$.

As shown in Figure 16(b), the duration of the change in the contact force is greater than that in the traditional model.
When the ball is still far from the defect edge, the contact force decreases. In the proposed model, this distance is the semiminor axis of the contact ellipse, the time for the ball to travel this distance is $b / 2 \pi f_{c} R_{o}$, and the total duration of the change in the contact force when the ball passes over the defect is $(L+b) / \pi f_{c} R_{o}$. The value of the semiminor axis of the contact ellipse is constantly changing and is determined by the applied load on the ball. Therefore, with an increase of 
TABLE 4: Relationships of $\Delta-a-b$.

\begin{tabular}{lcc}
\hline Sinking depth $\left(10^{-3} \mathrm{~mm}\right)$ & Semimajor axis $a(\mathrm{~mm})$ & Semiminor axis $b(\mathrm{~mm})$ \\
\hline 0.8 & 0.3046 & 0.0485 \\
1.0 & 0.3405 & 0.0543 \\
1.2 & 0.3730 & 0.0595 \\
1.4 & 0.4029 & 0.0642 \\
1.6 & 0.4307 & 0.0687 \\
1.8 & 0.4569 & 0.0728 \\
2.0 & 0.4816 & 0.0768 \\
2.2 & 0.5051 & 0.0805 \\
\hline
\end{tabular}

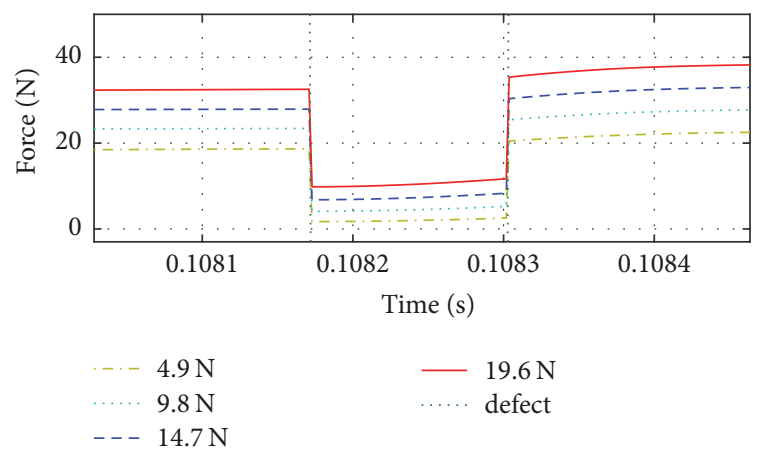

(a) Traditional model

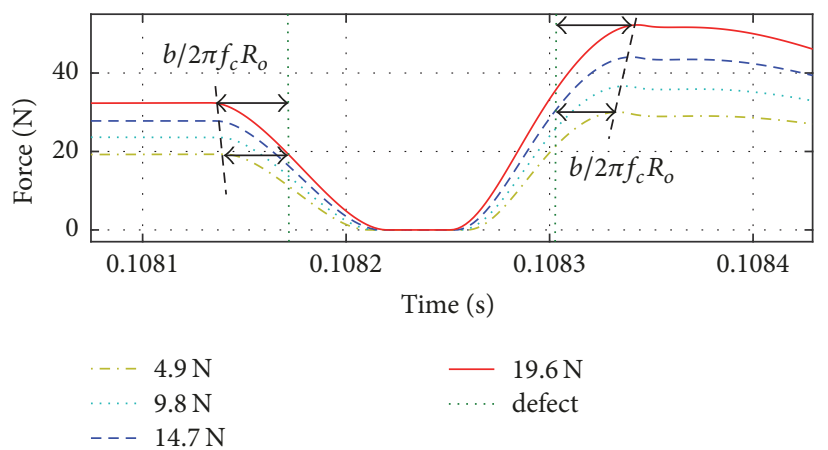

(b) Proposed model

FIGURE 16: Ball-raceway contact forces in the defect area under different loads.

the applied additional load (from $4.9 \mathrm{~N}$ to $19.6 \mathrm{~N}$ ), the total duration of the change in the contact force becomes longer.

\section{Conclusions}

A model for predicting the vibration response of ball bearings with a localized defect based on the Hertzian contact stress distribution is proposed. The mechanism of the vibration response in the defect area and the solution method of the traditional model are analysed. The Hertzian contact stress distribution and the contact area are used to calculate the ball-raceway contact force in the defect area. An experiment using a ball bearing with a defect in the outer raceway is performed, and the vibration responses of the experimental and numerical signals are compared to verify the applicability of the proposed model. Comparisons between the traditional model and the proposed model show that, unlike in the traditional model, in the proposed model, with an increase in the applied load, the sinking depth of balls in the defect area increases, and the contact force begins to change before the ball enters the defect region and stops changing after the ball leaves the defect region.

\section{Conflicts of Interest}

The authors declare that they have no conflicts of interest.

\section{Acknowledgments}

This work was supported by the National Natural Science Foundation of China (51175102) and the Fundamental
Research Funds for the Central Universities (Grant no. HIT.NSRIF.201638).

\section{References}

[1] S. Singh, C. Q. Howard, and C. H. Hansen, "An extensive review of vibration modelling of rolling element bearings with localised and extended defects," Journal of Sound and Vibration, vol. 357, pp. 300-330, 2015.

[2] P. D. McFadden and J. D. Smith, "Model for the vibration produced by a single point defect in a rolling element bearing," Journal of Sound and Vibration, vol. 96, no. 1, pp. 69-82, 1984.

[3] P. D. McFadden and J. D. Smith, "The vibration produced by multiple point defects in a rolling element bearing," Journal of Sound and Vibration, vol. 98, no. 2, pp. 263-273, 1985.

[4] A. Rafsanjani, S. Abbasion, A. Farshidianfar, and H. Moeenfard, "Nonlinear dynamic modeling of surface defects in rolling element bearing systems," Journal of Sound and Vibration, vol. 319, no. 3-5, pp. 1150-1174, 2009.

[5] N. Tandon and A. Choudhury, "An analytical model for the prediction of the vibration response of rolling element bearings due to a localized defect," Journal of Sound and Vibration, vol. 205, no. 3, pp. 275-292, 1997.

[6] A. Choudhury and N. Tandon, "Vibration response of rolling element bearings in a rotor bearing system to a local defect under radial load," Journal of Tribology, vol. 128, no. 2, pp. 252261, 2006.

[7] N. Sawalhi and R. B. Randall, "Simulating gear and bearing interactions in the presence of faults. Part I. The combined gear bearing dynamic model and the simulation of localised bearing faults," Mechanical Systems and Signal Processing, vol. 22, no. 8, pp. 1924-1951, 2008. 
[8] N. Sawalhi and R. B. Randall, "Simulating gear and bearing interactions in the presence of faults. Part II. Simulation of the vibrations produced by extended bearing faults," Mechanical Systems and Signal Processing, vol. 22, no. 8, pp. 1952-1966, 2008.

[9] N. S. Feng, E. J. Hahn, and R. B. Randall, "Using transient analysis software to simulate vibration signals due to rolling element bearing defects," Applied Mechanics, pp. 689-694, 2002.

[10] V. N. Patel, N. Tandon, and R. K. Pandey, "A dynamic model for vibration studies of deep groove ball bearings considering single and multiple defects in races," Journal of Tribology, vol. 132, no. 4, Article ID 041101, 10 pages, 2010.

[11] V. N. Patel, N. Tandon, and R. K. Pandey, "Vibration studies of dynamically loaded deep groove ball bearings in presence of local defects on races," in Proceedings of the 2013 International Conference on Design and Manufacturing, IConDM 2013, pp. 1582-1591, India, July 2013.

[12] M. S. Patil, J. Mathew, P. K. Rajendrakumar, and S. Desai, "A theoretical model to predict the effect of localized defect on vibrations associated with ball bearing," International Journal of Mechanical Sciences, vol. 52, no. 9, pp. 1193-1201, 2010.

[13] A. Moazen Ahmadi, D. Petersen, and C. Howard, "A nonlinear dynamic vibration model of defective bearings - The importance of modelling the finite size of rolling elements," Mechanical Systems and Signal Processing, vol. 52-53, no. 1, pp. 309-326, 2015.

[14] J. Liu, Y. Shao, and T. C. Lim, "Vibration analysis of ball bearings with a localized defect applying piecewise response function," Mechanism and Machine Theory, vol. 56, pp. 156-169, 2012.

[15] J. L. Gomez, A. Bourdon, H. André, and D. Rémond, "Modelling deep groove ball bearing localized defects inducing instantaneous angular speed variations," Tribology International, vol. 98, pp. 270-281, 2016.

[16] C. Mishra, A. K. Samantaray, and G. Chakraborty, "Ball bearing defect models: A study of simulated and experimental fault signatures," Journal of Sound and Vibration, vol. 400, pp. 86-112, 2017.

[17] A. Chen and T. R. Kurfess, "A new model for rolling element bearing defect size estimation," Measurement, vol. 114, pp. 144149, 2018.

[18] T. A. Harris, Rolling Bearing Analysis, Wiley, 1984.

[19] S. Khanam, J. K. Dutt, and N. Tandon, "Impact force based model for bearing local fault identification," Journal of Vibration and Acoustics, vol. 137, no. 5, Article ID 051002, 2015.

[20] G. Genta, "On a persistent misunderstanding of the role of hysteretic damping in rotordynamics," Journal of Vibration and Acoustics, vol. 126, no. 3, pp. 459-461, 2004.

[21] D. R. Harting, "Incipient failure detection by demodulated resonance analysis," Instrumentation Technology, vol. 9, pp. 5963, 1977. 


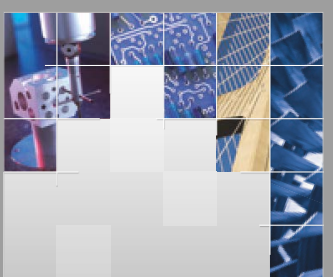

\section{Enfincering}
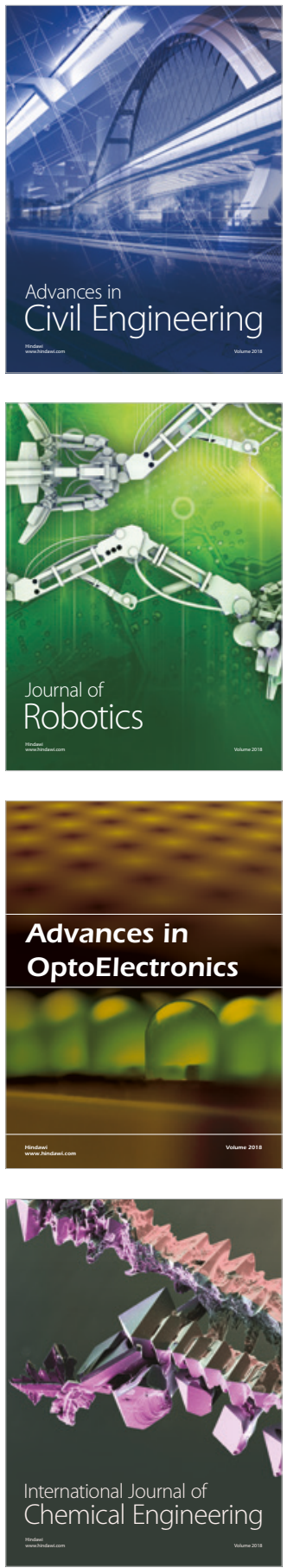

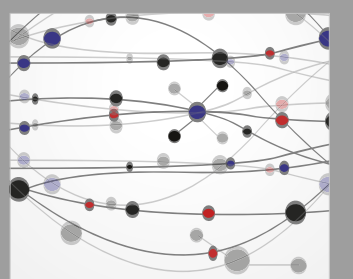

\section{Rotating \\ Machinery}

The Scientific World Journal

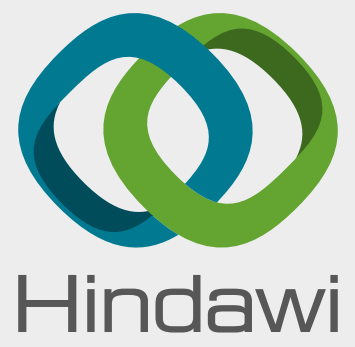

Submit your manuscripts at

www.hindawi.com
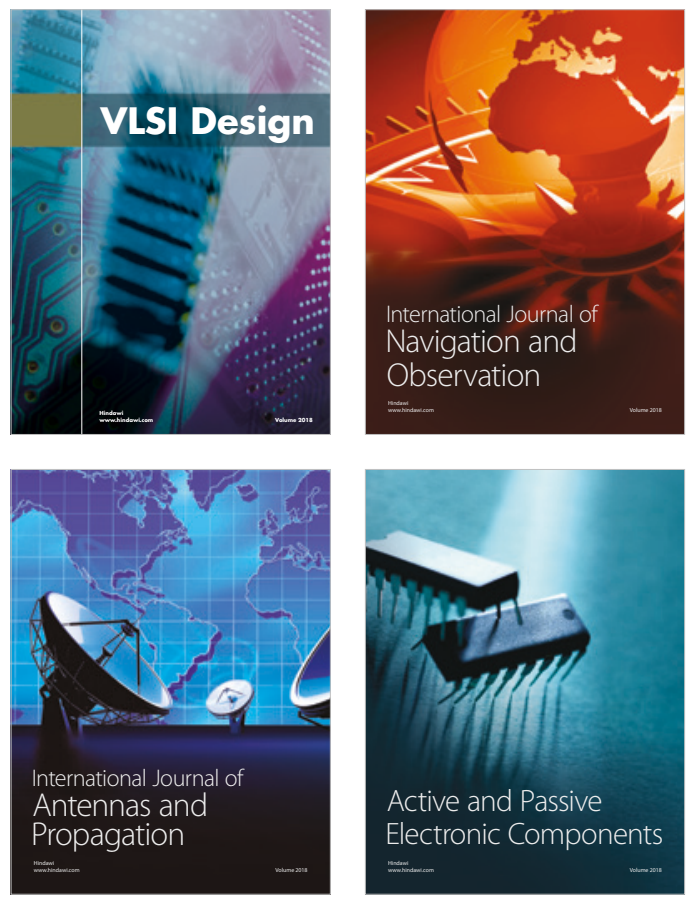
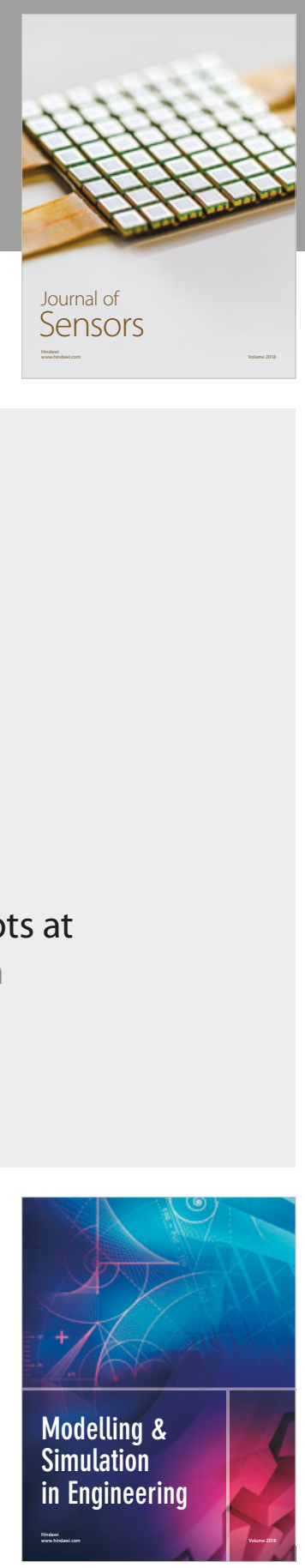

\section{Advances \\ Multimedia}
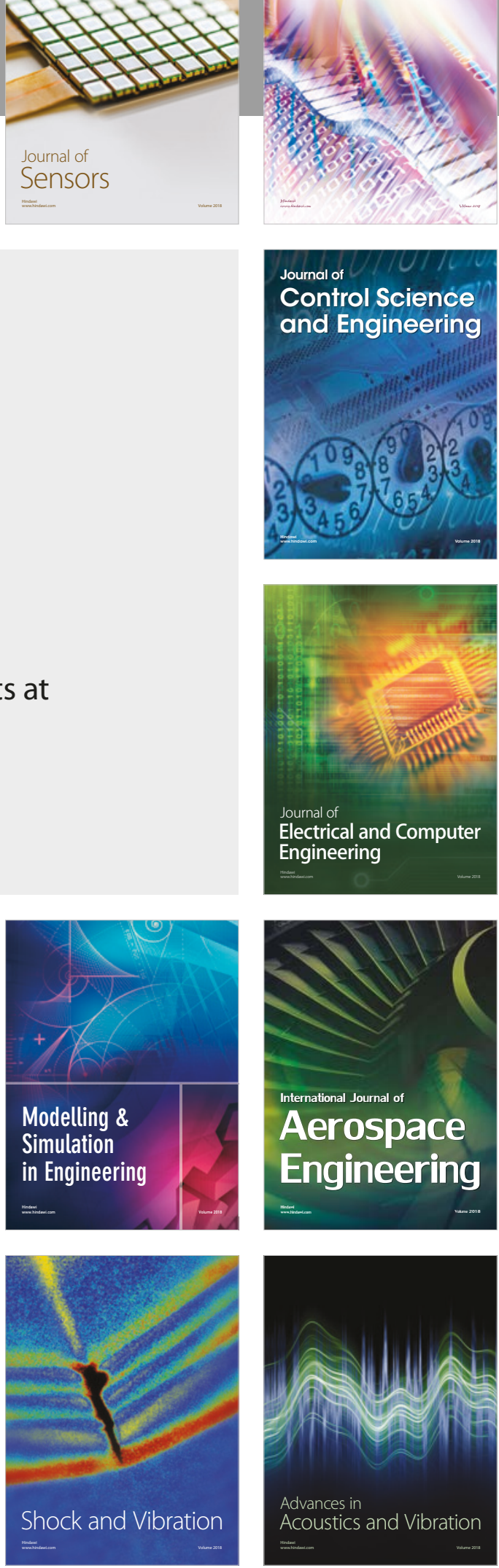